\title{
Assessment of the Affordability of Out-of-Pocket Payments among Some Selected People Living with HIV in Kano, Nigeria
}

\author{
Ibrahim Jahun1 (1), Mustapha Mukhtar², Aminu Yakubu³, Musa Zakirai ${ }^{4}$, \\ Bamidele Moyosola5 , Ahmad Aliyu', Abdulrazaq G. Habib7, Gambo Aliyu ${ }^{1}$ \\ ${ }^{1}$ National Agency for the Control of AIDS (NACA), Abuja, Nigeria \\ ${ }^{2}$ Department of Economics, Bayero University Kano, Kano, Nigeria \\ ${ }^{3} 54$ gene Laboratories, Lekki Lagos, Nigeria \\ ${ }^{4}$ National Population Commission, Abuja, Nigeria \\ ${ }^{5}$ School of Global Health and Bioethics, EUCLID University, Banjul, The Gambia \\ ${ }^{6}$ Institute of Human Virology Nigeria (IHVN), Abuja, Nigeria \\ ${ }^{7}$ Department of Medicine, Bayero University Kano, Kano, Nigeria \\ Email: drjahun@yahoo.co.uk, algambo@yahoo.com, muktaronline@gmail.com, yaminads@yahoo.com, \\ musazakirai@hotmail.com,moyosola@euclidfaculty.net, ataliyu@gmail.com,abdulrazaq_habib@yahoo.co.uk
}

How to cite this paper: Jahun, I., Mukhtar, M., Yakubu, A., Zakirai, M., Moyosola, B., Aliyu, A., Habib, A.G. and Aliyu, G. (2021) Assessment of the Affordability of Out-ofPocket Payments among Some Selected People Living with HIV in Kano, Nigeria. World Journal of AIDS, 11, 71-83.

https://doi.org/10.4236/wja.2021.112007

Received: April 19, 2021

Accepted: June 27, 2021

Published: June 30, 2021

Copyright $\odot 2021$ by author(s) and Scientific Research Publishing Inc. This work is licensed under the Creative Commons Attribution International License (CC BY 4.0).

http://creativecommons.org/licenses/by/4.0/

\begin{abstract}
Introduction: With an estimated 1.8 million People Living with HIV (PLHIV), Nigeria's HIV response is still heavily donor dependent. However, with anticipated decline in donor funding for HIV/AIDS program as the country takes ownership of the program, understanding financing options for PLHIV is important. One of such financing options is affordability of out-of-pocket payments (OOP) for anti-retroviral drugs (ARV) by PLHIV. We assessed affordability of OOP payments for ARVs in Kano State, North-Western Nigeria. Methods: Four Hundred and sixty-nine PLHIV receiving donor-supported-free ARV in Kano, North Western Nigeria were systematically selected and interviewed during routine clinic visits. Affordability for ARV was assessed by a combination of variables including willingness and financial means to incur extra expense for full dose of ARV based on landing and distribution cost of 8.3 USD (about 3,000 NGN) per month dose. Results: Four hundred and sixty-nine respondents were interviewed. Of those, 72 (15.4\%, 95\% CI: [13.2 - 19.7]) can afford ARV OOP on monthly base. The proportion of males able to pay 3,000 NGN (8.3 USD) or more OOP for ARVs was not different from that of women (15.5\% versus $15.2 \%)$. Attending school, education level, employment, monthly income and wealth have all been found to be associated with willingness and ability to pay for monthly dose of ARV OOP ( $\mathrm{p}<0.0001)$. Conclusion/recommendation: Majority of PLHIV in Kano
\end{abstract}


State may not afford ARV OOP in the event of withdrawal of supports by international donors. Innovative sustainable financing mechanisms from domestic resources are needed for HIV program sustainability.

\section{Keywords}

PLHIV, HIV Program Sustainability, HIV Out of Pocket Payments, Catastrophic HIV Expenditure

\section{Introduction}

Nigeria ranks fourth in HIV burden in the world after South Africa Mozambique and India with an estimated 1.8 million People Living with HIV (PLHIV) according to UNAIDS 2019 estimates [1]. The national prevalence of HIV stands at $1.3 \%$ among persons between the ages of 15 to 49 years [2]. Despite high HIV burden, Nigeria's response is substantially financed by international donor agencies. Since 2003 The U.S. President's Emergency Plan for AIDS Relief (PEPFAR) has been supporting countries across the globe to fight the epidemic with cumulative investment of over $\$ 85$ billion for the period 2003 to 2019 [3]. In Nigeria, PEPFAR invested over $\$ 5$ billion from 2004 to 2019 to support the national response to provide free HIV care and treatment services [4]. The mean cost of Anti-retroviral therapy (ART) per patient-year for a pediatric patient is estimated at $\$ 837$ while that for adult patient is $\$ 747$; PEPFAR, provides $\$ 341$ and $\$ 312$ to support pediatric and adult per patient-year costs for ART treatment respectively [5]. Nigeria contributes substantially to the routine public health service delivery such as human resource for health (HRH) and other related indirect costs that are part of routine healthcare management. However, donor funding for HIV/AIDS control efforts to Low and Middle Income Countries (LMICs) has been decreasing. Between 2015-2016, the funds provided by donors to support the HIV control efforts declined by about 7\% [6]. In between there were fluctuations as countries approach epidemic control.

Since then, although funding increased in 2017 and 2018, the increases did not match pre-2015 levels, in fact, a further decline of $\$ 165$ million was recorded in 2019 compared to 2018 [7]. With this trend, there are concerns that as countries achieved epidemic control, ownership and sustainability may be a challenge by LMICs. Available data shows that only a few LMICs are able to make significant investments in their own country's HIV control efforts. For example, India and South Africa were reported to pay for about $90 \%$ and $70 \%$ respectively, of their country's HIV response [8].

In Nigeria, since 2010 domestic funding has consistently been on the decline (below 25\% of total HIV funding), reaching its lowest level in 2018, where domestic resources accounted for less than $2 \%$ of the funding for the national response [9]. The government spending on health, which is the most significant source of financing to achieving the Universal Health Coverage (UHC) 
has remained below $16 \%$ for over a decade now. In 2018, the government accounted for only $14.1 \%$ of the total health expenditure in the country, with outof-pocket expenditure (OOPE) accounting for $77 \%$ of domestic health expenditure [10]. Government of Nigeria per capita spending was $\$ 12.5$ per capita as against the recommended $\$ 86$ per capita required to achieve UHC [11]. Nigeria is therefore unlikely to be able to put up additional resources that would be required to sustain HIV control efforts in the country. However, the National Agency for the Control of AIDS (NACA) is working with Nigerian Business Coalition against AIDS (NIBUCAA) to establish an HIV Trust Fund which will be private sector driven to support the national response and HIV program sustainability thereby closing some gaps that will emerge with the eventual exit of the international donors [12]. Data on feasibility of shouldering out-of-pocket payments (OOP) by PLHIV in Nigeria were largely from Southern part of the country. Mbachu et al., reported that PLHIV in the South will be willing to pay up to 15.3 USD per month dose of ARV drugs; willingness to pay was found to be associated with employment and higher socioeconomic status [13]. In another study, Adebimpe et al., reported that $68 \%$ of the study population in the South were willing to pay up to 20 USD for a month dose of ARV drugs [14]. To our knowledge, there are no such data from the Northern part of the country. Considering the wide variability in poverty headcount between states in Nigeria's various zones across Northern and Southern regions [15], knowledge of the proportion of PLHIV from the North likely to shoulder OOP payments for ARVs in the absence of free services will guide and inform planning for HIV services sustainability in different regions of Nigeria. In this paper, we report affordability of outof-pocket payments (OOP) for ARV drugs by PLHIV in Kano State, North-Western Nigeria.

\section{Methods}

\subsection{Settings}

This study was conducted in August 2018 in Kano State, North-West Nigeria. The state has a population of about 20 million, land mass of $20,131 \mathrm{~km}^{2}$ and 89 HIV treatment centers. The poverty headcount index in Kano State is $55.1 \%$ which is above national average of $40.1 \%$ [15]. HIV prevalence in Kano is $0.8 \%$ which is lower than the National average of $1.3 \%$ [2]. However, it has an estimated 44,837 PLHIV, [16] of which 25,659 were identified and currently receiving free donor-funded HIV care and treatment services [17].

\subsection{Study Sites and Design}

This was a cross-sectional study involving PLHIV receiving comprehensive ART services in Kano State. Four healthcare facilities that account for $65 \%$ of the PLHIV on treatment in the state were purposively selected for the study: a tertiary (Aminu Kano Teaching Hospital), a secondary (Murtala Muhammed Specialist Hospital), an infectious disease (Infectious Diseases Hospital, Kano) and a 
faith-based facility (Al-Noury Specialist Hospital, Kano). This selection provided good representation for different socioeconomic groups in the state. A total of 474 PLHIV were systematically selected from these four healthcare facilities proportionate to the number of PLHIV on treatment in each of them. The protocol for this survey was reviewed and approved by the ethical committees (Institutional Review Boards) of Kano State Ministry of Health and Aminu Kano Teaching Hospital.

\subsection{Sample Size and Sampling Technique}

The sampling frame was the pharmacy daily dispensing worksheets which provided accurate number of individuals who are active on treatment (ART). In the context of HIV/AIDS program, an active patient on ART is a patient who received ARV within the last 3 months. The minimum sample size estimated 351, after controlling for non-response rate and additional respondents who indicated interest to participate, the total number approached for consent was 474 (Table 1 ). The number enrolled in each facility was calculated by probability proportionate to size of number of PLHIV the facility has on treatment (Table 1). To minimize selection bias, systematic random sampling technique was used to select the respondents that were interviewed during each interview visit from list of patients scheduled for the clinic visit. Patients selected in previous visits were excluded. One out of every three of them was selected to participate. The random start was determined by using a random number application that was installed on the electronic data capture (EDC), thereafter kth number was determined by adding the selection interval $(\mathrm{k})$.

\subsection{Data Collection, Management, and Analysis}

Data were collected electronically by trained interviewers using computer-assisted personal interviewing. Structured questionnaires were administered to participants who consented to participate in the study. The questionnaire included questions on respondent's background information (sociodemographic information), household possessions and means of transportation, health seeking behavior and

Table 1. Distribution of sampled PLHIV respondents by facility.

\begin{tabular}{ccccc}
\hline Facility & PLHIV & Facility & $\begin{array}{c}\text { Expected PLHIV to be } \\
\text { sampled (after } \\
\text { on ART }\end{array}$ & $\begin{array}{c}\text { Actual PLHIV } \\
\text { seight } \\
\text { sampled } \\
\text { (individuals } \\
\text { non-response) } \\
\text { approached for } \\
\text { consent) }\end{array}$ \\
\hline Aminu Kano Teaching Hospital, Kano & 7,749 & 0.4 & 190 & 204 \\
Infectious Diseases Hospital Kano & 5,779 & 0.3 & 141 & 147 \\
Murtala Muhammed Specialist Hospital, Kano & 3,592 & 0.2 & 88 & 91 \\
Al-Noury Specialist Hospital, Kano & 1,253 & 0.1 & 31 & 32 \\
Total & 18,373 & 1.0 & 450 & 474
\end{tabular}

Abbreviations: PLHIV_-People Living with HIV; ART_-Antiretroviral treatment. 
other indirect expenses associated with seeking of HIV care. Additionally, respondents were asked how much in addition to routine HIV related expenses such as transportation, laboratory tests and treatment of opportunistic infections they could afford to incur for a month dose of ARV drugs if they were to pay out-of-pockets based on a range of additional expenses, from not able to afford OOP (none), to affordability below the amount needed to pay for ARV (less than 3,000 NGN [8.3USD]) and affordability equal or above 3,000 NGN (8.3USD). We thus defined affordability in the context of this study as willingness (yes or no) and ability of an HIV infected individual on ART to pay 3,000 NGN (8.3 USD) for a month dose of ARV beside all other expenses associated with management of HIV infection. Three thousand Naira (8.3 USD) at the time of the study is the landing and last mile distribution cost of a month dose of ARV including indirect cost associated with storage and dispensing at facility level (personal communication with Nigerian Agency for the Control of AIDS). Completed questionnaires were synchronized to a central server in real-time immediately after completion of each interview. Data was analyzed using STATA version 14.2 software. Frequency distributions and proportions of persons who are willing and can incur extra expenses above routine were computed. Baseline demographic and related covariates were examined in univariate analyses. Differences in proportions between the categorical groups were evaluated using Chi-square test to determine significance of associations between the groups. Two sided $P$-values of 0.05 or less were considered statistically significant.

For estimating the socio-economic status (SES), an SES index was developed using principal component analysis (PCA) as described by Edwards JH and Edwards AWF [18]. The input into the PCA was the information on households' ownership of key possessions. The index was used to divide the individuals into five SES groups (quintiles), namely Q1 (poorest), Q2 (second), Q3 (third), Q4 (fourth) and Q5 (wealthiest). Chi-square for trend analysis was applied for all disaggregation of key dependent variables by SES quintiles.

\section{Results}

Of the 474 respondents who indicated interest and approached for consent to participate in the study, 469 (98.9\%) were interviewed. Mean age of the study participants was $39.8(\mathrm{SD}=10.6)$. Men were older, mean $=44.2(\mathrm{SD}=9.9)$ years compared to females: $37.6(\mathrm{SD}=10.3)$ years. Majority of the men $(77.6 \%)$ were married and 150 (83.3\%) of them were married to one wife. Conversely only 115 $(48.5 \%)$ of the women were married (Table 2 ). Men were more gainfully employed compared to women ( $87.5 \%$ versus $67.5 \%)$ and men were equally more educated (Table 2).

All respondents expressed willingness to pay OOP. However, only72(15.4\%, 95\% CI: [13.2-19.7]) can afford OOP for the monthly dose of ARV. Attending school, education level, employment, monthly income are found to be associated with OOP $(\mathrm{p}<0.0001)$ (Table 3$)$. 
Respondents who reported higher monthly income of 50,000 NGN or more are more likely to incur additional expenses for management of their HIV infection compared to those who reported lower monthly income of 10,000 NGN or less (30.0\% versus $9.4 \%$ ) A similar trend is seen among respondents in the richest wealth quintile compared to those in the poorest wealth quintile $(23.1 \%$ versus $6.3 \%$ ) (Table 3 ).

The proportion of males able to pay 3,000 NGN (8.3 USD) or more OOP for ARVs was not different from that of women (15.5\% versus $15.2 \%$ ) (Table 4 ).

Table 2. Socioeconomic and demographic characteristics of PLHIV in Kano State, North-Western Nigeria by sex, August 2018.

\begin{tabular}{|c|c|c|c|c|c|c|}
\hline & \multicolumn{2}{|c|}{ Male } & \multicolumn{2}{|c|}{ Female } & \multicolumn{2}{|c|}{ Total } \\
\hline & $\begin{array}{l}\text { Frequency } \\
(\mathrm{N}=232)\end{array}$ & Percent (\%) & $\begin{array}{c}\text { Frequency } \\
(N=237)\end{array}$ & Percent (\%) & $\begin{array}{l}\text { Frequency } \\
(\mathrm{N}=469)\end{array}$ & Percent (\%) \\
\hline \multicolumn{7}{|l|}{ Age (years) } \\
\hline$<18$ & 3 & 1.3 & 4 & 1.7 & 7 & 1.5 \\
\hline $18-20$ & 1 & 0.4 & 10 & 4.2 & 11 & 2.3 \\
\hline $21-24$ & 12 & 5.2 & 32 & 13.5 & 44 & 9.4 \\
\hline $25-29$ & 20 & 8.6 & 53 & 22.4 & 73 & 15.6 \\
\hline $30-34$ & 37 & 16 & 47 & 19.8 & 84 & 17.9 \\
\hline $35-39$ & 97 & 41.8 & 62 & 26.2 & 159 & 33.9 \\
\hline $40-49$ & 62 & 26.7 & 29 & 12.2 & 91 & 19.4 \\
\hline $50+$ & - & - & - & - & - & - \\
\hline Total & 232 & 49.5 & 237 & 50.5 & 469 & \\
\hline Mean age (SD) & $44.2(9.9)$ & & $37.6(10.3)$ & & & \\
\hline \multicolumn{7}{|l|}{ Marital status } \\
\hline Single & 33 & 14.2 & 19 & 8 & 52 & 11.1 \\
\hline Married & 180 & 77.6 & 115 & 48.5 & 295 & 62.9 \\
\hline Divorced & 8 & 3.5 & 24 & 10.1 & 32 & 6.8 \\
\hline Widowed & 11 & 4.7 & 78 & 32.9 & 89 & 19.0 \\
\hline Separated & - & - & 1 & 0.4 & 1 & 0.2 \\
\hline \multicolumn{7}{|l|}{ Employment status } \\
\hline Not employed & 39 & 16.8 & 110 & 46.5 & 149 & 31.8 \\
\hline Employed & 193 & 83.2 & 127 & 53.5 & 320 & 68.2 \\
\hline \multicolumn{7}{|l|}{ Monthly income in NGN (USD) } \\
\hline$<10,000(<29)$ & 61 & 31.7 & 69 & 54.8 & 130 & 40.6 \\
\hline $10,000-20,000(29-48)$ & 47 & 24.4 & 24 & 18.5 & 71 & 22.2 \\
\hline $20,001-50,000(49-139)$ & 52 & 27 & 26 & 20.2 & 78 & 24.4 \\
\hline $50,001-100,000(140-278)$ & 33 & 16.9 & 8 & 6.5 & 41 & 12.8 \\
\hline
\end{tabular}

Abbreviations: PLHIV—People living with HIV; NGN—Nigerian Naira; USD—US Dollar. 
Table 3. Correlates of out-of-pocket payments for ARV among PLHIV in Kano State, North-Western Nigeria, August 2018.

\begin{tabular}{|c|c|c|c|c|c|c|c|c|}
\hline OOP in NGN (USD)/month & None & $\begin{array}{l}<500 \\
(<1.4)\end{array}$ & $\begin{array}{l}500-<1000 \\
(1.4-<2.8)\end{array}$ & $\begin{array}{c}1000-<3000 \\
(2.8-<8.3)\end{array}$ & $\begin{array}{c}3000-<5000 \\
(8.3-<13.9)\end{array}$ & $\begin{array}{c}5000-10,000 \\
(13.9-27.8)\end{array}$ & Total & $\begin{array}{c}\text { Chi-square } \\
\text { (P-Value) }\end{array}$ \\
\hline Characteristics & $126(26.9)$ & $109(23.2)$ & $112(23.9)$ & $50(10.7)$ & $23(4.9)$ & $49(10.4)$ & $469(100.0)$ & \\
\hline \multicolumn{9}{|l|}{ Age } \\
\hline $10-20$ & $2(28.6)$ & $2(28.6)$ & $0(0.0)$ & $2(28.6)$ & $0(0.0)$ & $1(14.3)$ & $7(100.0)$ & $36(0.065)$ \\
\hline $21-24$ & $2(18.2)$ & $1(9.1)$ & $1(9.1)$ & $2(18.2)$ & $2(18.2)$ & $3(27.3)$ & $11(100.0)$ & \\
\hline $25-29$ & $6(13.6)$ & $14(31.8)$ & $12(27.3)$ & $3(6.8)$ & $2(4.6)$ & $7(15.9)$ & $44(100.0)$ & \\
\hline $30-34$ & $22(30.1$ & $19(26.0)$ & $18(24.7)$ & $5(6.9)$ & $2(2.7)$ & $7(8.6)$ & $73(100.0)$ & \\
\hline $35-39$ & $23(27.4)$ & $18(21.4)$ & $21(25.0)$ & $8(9.5)$ & $9(10.7)$ & $5(6.0)$ & $84(100.0)$ & \\
\hline $40-49$ & $43(27.0)$ & $33(20.8)$ & $36(22.6)$ & $18(11.3)$ & $7(4.4)$ & $22(13.9)$ & $159(100.0)$ & \\
\hline $50+$ & $28(30.8)$ & $22(24.2)$ & $24(26.4)$ & $12(13.2)$ & $1(1.1)$ & $4(4.4)$ & $91(100.0)$ & \\
\hline \multicolumn{9}{|l|}{ Sex } \\
\hline Male & $51(22.0)$ & $46(19.8)$ & $60(25.9)$ & $39(16.8)$ & $10(4.3)$ & $26(11.2)$ & $232(100.0)$ & $26.3(0.000)$ \\
\hline Female & $75(31.7)$ & $63(26.6)$ & $52(21.9)$ & $11(4.6)$ & $13(5.5)$ & $23(9.7)$ & $237(100.0)$ & \\
\hline \multicolumn{9}{|l|}{ Ever attended school } \\
\hline No & $47(48.0)$ & $21(21.4)$ & $16(16.3)$ & $8(8.2)$ & $1(1.0)$ & $5(5.0)$ & $98(100.0)$ & $31.6(0.000)$ \\
\hline Yes & $79(21.3)$ & $88(23.7)$ & $96(25.9)$ & $42(11.3)$ & $22(5.9)$ & $44(11.9)$ & $371(100.0)$ & \\
\hline \multicolumn{9}{|l|}{ Level of education } \\
\hline Primary & $37(36.6)$ & $30(29.7)$ & $23(22.8)$ & $6(5.9)$ & $2(2.0)$ & $3(3.0)$ & $101(100.0)$ & $43.2(0.000)$ \\
\hline Secondary & $27(19.0)$ & $26(18.3)$ & $37(26.1)$ & $22(15.5)$ & $13(9.2)$ & $17(11.9)$ & $142(100.0)$ & \\
\hline Tertiary & $15(11.7)$ & $32(25.0)$ & $36(28.1)$ & $14(10.9)$ & $7(5.5)$ & $24(18.7)$ & $128(100.0)$ & \\
\hline \multicolumn{9}{|l|}{ Employment status } \\
\hline Not employed & $61(39.1)$ & $42(26.9)$ & $29(18.6)$ & $9(5.8)$ & $6(3.8)$ & $9(5.8)$ & $156(100.0)$ & \\
\hline Employed & $65(20.8)$ & $67(21.4)$ & $83(26.5)$ & $41(13.1)$ & $17(5.4)$ & $40(12.8)$ & $313(100.0)$ & \\
\hline \multicolumn{9}{|l|}{ Monthly income in NGN (USD) } \\
\hline$<10,000(<27.8)$ & $41(32.0)$ & $32(25.0)$ & $33(25.8)$ & $10(7.8)$ & $2(1.6)$ & $10(7.8)$ & $128(100.0)$ & $55.1(0.000)$ \\
\hline $10,000-20,000(27.9-55.6)$ & $14(20.3)$ & $16(23.2)$ & $19(27.5)$ & $12(17.4)$ & $3(4.4)$ & $5(7.3)$ & $69(100.0)$ & \\
\hline $20,001-50,000(55.7-138.9)$ & $8(10.5)$ & $12(15.8)$ & $20(26.3)$ & $15(19.7)$ & $9(11.8)$ & $12(15.8)$ & $76(100.0)$ & \\
\hline $50,001-100,000(139.0-277.8)$ & $2(5.0)$ & $7(17.5)$ & $11(27.5)$ & $4(10.0)$ & $3(7.5)$ & $13(22.5)$ & $40(100.0)$ & \\
\hline \multicolumn{9}{|l|}{ Wealth quintile } \\
\hline Poorest & $46(40.7)$ & $26(23.0)$ & $27(23.9)$ & $7(6.2)$ & $2(1.8)$ & $5(4.5)$ & $113(100.0)$ & $53.9(0.000)$ \\
\hline Poorer & $27(31.0)$ & $25(28.7)$ & $16(18.4)$ & $10(11.5)$ & $3(3.5)$ & $6(6.8)$ & $87(100.0)$ & \\
\hline Middle & $16(17.4)$ & $26(28.3)$ & $28(30.4)$ & $9(9.8)$ & $6(6.5)$ & $7(7.6)$ & $92(100.0)$ & \\
\hline Richer & $32(25.6)$ & $21(16.8)$ & $25(20.0)$ & $16(12.8)$ & $7(5.6)$ & $24(19.2)$ & $125(100.0)$ & \\
\hline Richest & $5(9.6)$ & $11(21.2)$ & $16(30.8)$ & $8(15.4)$ & $5(9.6)$ & $7(13.5)$ & $52(100.0)$ & \\
\hline
\end{tabular}

Abbreviations: ARV—Antiretroviral drugs; PLHIV—People living with HIV; NGN—Nigeria Naira; [1 USD = 360 NGN]. 
Table 4. Out-of-pocket payments for ARV by cost category by sex among PLHIV in Kano State, North-Western Nigeria, August 2018.

Total (male and female)

\begin{tabular}{|c|c|c|c|c|c|}
\hline & $\begin{array}{c}\text { Categories } \\
\text { (cost/month) in } \\
\text { NGN }\end{array}$ & $\begin{array}{l}\text { Frequency } \\
\text { per category }\end{array}$ & $\begin{array}{c}\text { Rel. frequency } \\
\text { per category } \\
(\%)\end{array}$ & $\begin{array}{l}\text { Lower bound on } \\
\text { frequencies } \\
(95 \%)\end{array}$ & $\begin{array}{l}\text { Upper bound on } \\
\text { frequencies } \\
(95 \%)\end{array}$ \\
\hline & $<500$ & 109 & 23.2 & 19.4 & 27.1 \\
\hline & $500-<1,000$ & 112 & 23.9 & 20.0 & 27.7 \\
\hline & $1,000-<3,000$ & 50 & 10.7 & 7.9 & 13.5 \\
\hline & $3,000-<5,000$ & 23 & 4.9 & 3.0 & 6.9 \\
\hline & $5,000-10,000$ & 49 & 10.4 & 6.2 & 14.6 \\
\hline & None & 126 & 26.9 & 22.9 & 30.9 \\
\hline \multicolumn{6}{|l|}{ Male } \\
\hline & $<\mathrm{N} 500$ & 46 & 19.8 & 14.7 & 25.0 \\
\hline & $500-<1,000$ & 60 & 25.9 & 20.2 & 31.5 \\
\hline & $1,000-<3,000$ & 39 & 16.8 & 12.0 & 21.6 \\
\hline & $3,000-<5,000$ & 10 & 4.3 & 1.7 & 6.9 \\
\hline & $5,000-10,000$ & 26 & 11.2 & 4.7 & 17.7 \\
\hline & None & 51 & 22.0 & 16.7 & 27.3 \\
\hline \multicolumn{6}{|c|}{ Female } \\
\hline & $<\mathrm{N} 500$ & 63 & 26.6 & 21.0 & 32.2 \\
\hline & $500-<1,000$ & 52 & 21.9 & 16.7 & 27.2 \\
\hline & $1,000-<3,000$ & 11 & 4.6 & 2.0 & 7.3 \\
\hline & $3,000-<5,000$ & 13 & 5.5 & 2.6 & 8.4 \\
\hline & $5,000-10,000$ & 23 & 9.7 & 4.3 & 15.1 \\
\hline & None & 75 & 31.6 & 25.7 & 37.6 \\
\hline
\end{tabular}

Abbreviations: ARV—Antiretroviral drugs; PLHIV—People living with HIV; NGN—Nigeria Naira [1 USD $=360 \mathrm{NGN}]$.

\section{Discussions}

This study examined whether PLHIV in Kano State are willing and can afford to pay for a month dose of ARV out of pocket (OOP) based on landing and distribution cost of 8.3 USD (about 3.000 NGN) per month dose of adult ARV, which hitherto, they had been receiving free. Predictably, a very low proportion of the respondents were found to be able to afford the minimum extra expense although all indicated willingness to pay but the majority cannot afford. However, among those that can afford we did not see differences between male and female PLHIV. These findings may be a reflection of levels of poverty in the State. It has a poverty headcount index of $55.1 \%$ with over half of the state population living on less than 361 USD/year [15]. Majority of the respondents' monthly income is below 29 USD, which is less than a dollar ( 1 USD $=360$ NGN) per day. This may 
have contributed to the lack of affordability of ARV OOP expense by the majority. Our findings show correlation between affordability of ARV OOP expense and education, employment and higher socioeconomic class. In South-Eastern Nigeria, a study by Mbatchu et al., reported PLHIV can afford to pay up to 15.3 USD OOP expense per month dose of ARV drugs and affordability was also found to be associated with employment and higher socioeconomic status [13]. Another study in Osun State, South-Western Nigeria, 68\% of the study population who expressed willingness to pay can afford to pay up to 20 USD OOP expense for a month dose of ARV drugs [14]. Therefore, affordability to pay for OOP expense for ARV drugs among PLHIV varies by region in Nigeria and appears to be predicted by levels of socioeconomic status of the populations, higher among PLHIV in the South and lower among those in the North [19].

Several studies have reported on the implication of HIV on households living standards in developing countries [20] [21] [22] whereby despite being on free ARV drugs, families are still being pushed to catastrophic health expenditures (CHE) due to costs associated with access to free HIV care services such as transportation costs and management of comorbidities. The WHO defines CHE as out-of-pocket spending for health care that exceeds a certain proportion of a household's income with the consequence that households suffer the burden of disease [23]. A vicious cycle of stigma, poverty and gender imbalance will continue to impact negatively on widowed PLHIV women thereby affecting their health outcomes in the context of HIV [24] [25] [26]. In South Africa, widow headed households are found to be subjected to series of financial, social, emotional and physical hardships and due to cultural issues, the households are rarely supported by relatives leaving them to rely heavily on government social supports, such as grants and pensions [27]. Unfortunately, such social welfares are not readily available or adequate in most African countries such as Nigeria.

In an effort to ensure sustainability of free HIV care and to stimulate country ownership in Nigeria, in October 2014 PEPFAR transitioned service provision to local indigenous organizations with substantial cuts in funding. Following this policy change by PEPFAR, there were observed reduction in quality of service at healthcare facilities due to reduced staff wages leading to decreased morale, increased patients lost to follow-up and inadequate laboratory monitoring of patients and introduction of user fees by over $90 \%$ of healthcare facilities [28]. This demonstrates the likelihood of potential catastrophic scenarios likely to happen to PLHIV especially in the North. Weak health system serves as major barrier to sustainability of public health interventions in developing countries as documented in reports from Mozambique, Rwanda and Zambia among others [29] [30] [31]. There is the need for states and Government of Nigeria to develop innovative sustainable financing mechanisms from domestic resources for HIV program sustainability.

Nigeria earmarks to health are mainly from payroll tax which is grossly inadequate [32]. Earmarking taxes on tobacco and vehicles or stores may be con- 
sidered to support sustainability of free HIV care service in Kano as the majority PLHIV cannot afford minimum OOP for ARV. With only $4 \%$ of Nigerians covered by National Health Insurance Scheme (NHIS) [33] [34] [35] [36], health insurance may not be a reliable strategy at this time to sustain free HIV care in Nigeria although social insurance has contributed up to $69 \%$ and $60 \%$ of HIV financing in LMIC countries of Colombia and Chile respectively [37]. Very Important Person (VIP) HIV Clinics or Executive HIV Clinics in private hospital where by high and middle income PLHIV are charged higher depending on their socioeconomic status was found to work in some settings. The extra charges from the wealthy PLHIV were used to subsidize HIV care and treatment for the poor PLHIV [38].

Our study has two key limitations. First, this study was conducted only in facilities that are within Kano metropolis. This could introduce a selection bias given that PLHIV who live in the metropolitan cities are likely to earn more and by implication afford more. However, we believe that the facilities selected for this study attend to a diverse section of the people from rural and urban parts of the state and our sample is likely to represent PLHIV in the state. All the four facilities have very high patient turn-over rates. Due to high population density, and limited health facilities in other states surrounding Kano, for example Murtala Muhammed Specialist Hospital has a very high turnover of patients, estimated at 18,000, monthly [39]. Second, we only used ARV costs reported elsewhere in Nigeria to assess affordability because of common procurement sources for ARVs with limited intra-country cost variability. Although cross-country variability in ARV costs have been reported [40] [41], we believe this is not the case in Nigeria since a common pipeline is used to procure HIV medicines and commodities in the country [42]. Although there are inter-facility variabilities in other OOP expenditures incurred in accessing HIV services, these do not affect the unit cost of the ARV themselves.

\section{Conclusion/Recommendations}

Majority of PLHIV in Kano State may not afford to pay OOP for ARV. There is no difference by sex in affordability of OOP among PLHIV receiving free HIV services in Kano State. Innovative sustainable financing mechanisms from domestic resources to aid HIV program sustainability are needed especially in states with high poverty headcount index in Northern Nigeria.

\section{Acknowledgements}

The authors gratefully thank PLHIV and leadership of the four healthcare facilities that participated in this study. Similarly, the diligence of field study teams is well appreciated.

\section{Conflicts of Interest}

The authors declare no conflicts of interest regarding the publication of this paper. 


\section{References}

[1] UNAIDS (2019) AIDS People Living with HIV-All Ages. https://aidsinfo.unaids.org/

[2] Federal Ministry of Health, Nigeria (2019) Nigeria HIV/AIDS Indicator and Impact Survey (NAIIS) 2018: Technical Report. Federal Ministry of Health, Abuja, Nigeria.

[3] The United States President's Emergency Plan for AIDS Relief (PEPFAR). https://www.state.gov/pepfar/

[4] US Embassy and Consulate in Nigeria (2020) PEPFAR. https://ng.usembassy.gov/embassy-consulate/abuja/sections-offices/pepfar/

[5] Randy, S. and PEPFAR Program (2012) On Costs of Treatment in the President's Emergency Plan for AIDS Relief (PEPFAR).

[6] UNAIDS and The Henry J Kaiser Family Foundation (2017) Donor Government Funding for HIV in Low- and Middle-Income Countries in 2016. The Henry J Kaiser Family Foundation, Washington DC.

[7] Kates, J., Wexler, A., Lief, E. and Joint United Nations Programme on HIV/AIDS (UNAIDS) (2019) Donor-Government-Funding for-HIV in Low and Middle-Income Countries 2019.

http://files.kff.org/attachment/Donor-Government-Funding-for-HIV-in-Low-andMiddle-Income-Countries-in-2019.pdf

[8] Funding for HIV and AIDS (Avert 2021) https://www.avert.org/professionals/hiv-around-world/global-response/funding\#fo otnote14 rdfzzgs

[9] Reem, H. (2018) Nigeria Health Financing System Assessment. Discussion Paper, World Bank Group, Washington DC.

http://documents1.worldbank.org/curated/en/782821529683086336/pdf/127519-W P-PUBLIC-add-series-NigeriaHFSAFINAL.pdf

[10] Global Burden of Disease Health Financing Collaborator Network (2019) Past, Present, and Future of Global Health Financing: A Review of Development Assistance, Government, Out-of-Pocket, and Other Private Spending on Health for 195 Countries, 1995-2050. The Lancet, 393, 2233-2260. https://doi.org/10.1016/S0140-6736(19)30841-4

[11] Mcintyre, D., Meheus, F. and Røttingen, J.A. (2017) What Level of Domestic Government Health Expenditure Should We Aspire to for Universal Health Coverage? Health Economics, Policy and Law, 12, 125-137. https://doi.org/10.1017/S1744133116000414

[12] National Agency for Control of HIV/AIDS (NACA) (2020) NACA Nigeria Unfolds Plan for \$150m HIV Trust Fund. https://naca.gov.ng/naca-unfolds-plan-for-150m-hiv-trust-fund/

[13] Mbachu, C., Okoli, C., Onwujekwe, O., \& Enabulele, F. (2018) Willingness to Pay for Antiretroviral Drugs among HIV and AIDS Clients in South-East Nigeria. Health Expectations, 21, 270-278. https://doi.org/10.1111/hex.12612

[14] Adebimpe, W.O., Badru, N.D., Adeoye, O.A. and Osifo, J. (2020) Willingness of People Living with Human Immunodeficiency Virus/Acquired Immunodeficiency Syndrome to Pay for Treatment and Preventive Services in Human Immunodeficiency Virus Care Centers in Osogbo, Osun State. Medical Journal of Babylon, 17, 84-88.

[15] Varrella, S. (2019) Poverty Headcount Rate in Nigeria as of 2019, by State. https://www.statista.com/statistics/1121438/poverty-headcount-rate-in-nigeria-by-s 
$\underline{\text { tatel }}$

[16] Nigeria Subnational HIV Estimates (UNAIDS Spectrum Model 2019) Based on NAIIS 2018 Data in: Revised National HIV and AIDS Strategic Framework, 20192021.

https://naca.gov.ng/wp-content/uploads/2019/03/NATIONAL-HIV-AND-AIDS-ST RATEGIC-FRAMEWORK-1.pdf

[17] PEPFAR Nigeria Annual Program Results (2020) Patients that Are Currently Receiving Antiretroviral Treatment (ART) by State in Nigeria.

[18] Edward Jackson, J. (1980) Principal Components and Factor Analysis: Part I-Principal Components. Journal of Quality Technology, 12, 201-213.

https://doi.org/10.1080/00224065.1980.11980967

[19] National Population Commission (NPC) [Nigeria] and ICF (2019) Nigeria Demographic and Health Survey 2018. National Population Commission and ICF, Abuja and Rockville. https://dhsprogram.com/pubs/pdf/FR359/FR359.pdf

[20] Dauda, R.S. (2018) HIV/AIDS and Economic Growth: Evidence from West Africa. The International Journal of Health Planning and Management, 34, 324-337. https://doi.org/10.1002/hpm.2633

[21] Bunyasi, E. W. and Coetzee, D.J. (2017) Relationship between Socioeconomic Status and HIV Infection: Findings from a Survey in the Free State and Western Cape Provinces of South Africa. BMJ Open, 7, e016232.

https://doi.org/10.1136/bmjopen-2017-016232

[22] Taraphdar, P., Guha, R.T., Haldar, D., Chatterjee, A., Dasgupta, A., Saha, B. and Mallik, S. (2011) Socioeconomic Consequences of HIV/AIDS in the Family System. Nigerian Medical Journal, 52, 250-253.

[23] Xu, K., Evans, D.B., Kawabata, K., et al. World Health Organizations (WHO, 2003) Household Catastrophic Health Expenditure: A Multi-Country Analysis. The Lancet, 362, 111-117.

https://www.who.int/health financing/documents/lancet-catastrophic expenditure. pdf

[24] Ramjee, G. and Daniels, B. (2013) Women and HIV in Sub-Saharan Africa. AIDS Research and Therapy, 10, Article No. 30. https://doi.org/10.1186/1742-6405-10-30

[25] Chaturaka, R. and Senaka, R. (2010) HIV, Poverty and Women. International Health, 2, 9-16. https://doi.org/10.1016/j.inhe.2009.12.003

[26] Aasha Kapur, M. and Sreoshi, G. (2005) The Impact of HIV AIDS on Women Care Givers in Situations of Poverty: Policy Issues. https://ssrn.com/abstract=1756789

[27] Schatz, E., Madhavan, S. and Williams, J. (2011) Female-Headed Households Contending with AIDS-Related Hardship in Rural South Africa. Health \& Place, 17, 598 605. https://doi.org/10.1016/j.healthplace.2010.12.017

[28] Banigbe, B., Audet, C.M., Okonkwo, P., Arije, O.O., Bassi, E., Clouse, K., et al. (2019) Effect of PEPFAR Funding Policy Change on HIV Service Delivery in a Large HIV Care and Treatment Network in Nigeria. PLOS ONE, 14, e0221809. https://doi.org/10.1371/journal.pone.0221809

[29] Rasschaert, F., Decroo, T., Remartinez, D., Telfer, B., Lessitala, F., Biot, M., et al. (2014) Sustainability of a Community-Based Anti-Retroviral Care Delivery Model-A Qualitative Research Study in Tete, Mozambique. Journal of the International AIDS Society, 17, Article No. 18910. https://doi.org/10.7448/IAS.17.1.18910 http://www.jiasociety.org/index.php/jias/article/view/18910

[30] Swain, J.D., Pugliese, D.N., Mucumbitsi, J., Rusingiza, E.K., Ruhamya, N., Kagame, 
A., et al. (2014) Partnership for Sustainability in Cardiac Surgery to Address Critical Rheumatic Heart Disease in Sub-Saharan Africa: The Experience from Rwanda. World Journal of Surgery, 38, 2205-2211. https://doi.org/10.1007/s00268-014-2559-2

[31] Torpey, K., Mwenda, L., Thompson, C., Wamuwi, E. and van Damme, W. (2010) From Project Aid to Sustainable HIV Services: A Case Study from Zambia. Journal of the International AIDS Society, 13, 19. https://doi.org/10.1186/1758-2652-13-19

[32] Prakongsai, P., Patcharanarumol, W., \& Tangcharoensathien, V. (2008) Can Earmarking Mobilize and Sustain Resources to the Health Sector? Bulletin of the World Health Organization, 86, 898-901. https://doi.org/10.2471/BLT.07.049593

[33] Onoka, C.A., Onwujekwe, O.E., Uzochukwu, B.S. and Ezumah, N.N. (2013) Promoting Universal Financial Protection: Constraints and Enabling Factors in Scaling-up Coverage with Social Health Insurance in Nigeria. Health Research Policy and Systems, 11, Article No. 20. https://doi.org/10.1186/1478-4505-11-20

[34] McIntyre, D., Ranson, M.K., Aulakh, B.K. and Honda, A. (2013) Promoting Universal Financial Protection: Evidence from Seven Low- and Middle-Income Countries on Factors Facilitating or Hindering Progress. Health Research Policy and Systems, 11, Article No. 36. https://doi.org/10.1186/1478-4505-11-36

[35] Okebukola, P.O. and Brieger, W.R. (2016) Providing Universal Health Insurance Coverage in Nigeria. International Quarterly of Community Health Education, 36, 241-246. https://doi.org/10.1177\%2F0272684X16657451

[36] Varrella, S. (2020) Health Insurance Coverage in Nigeria in 2018, by Type and Gender.

https://www.statista.com/statistics/1124773/health-insurance-coverage-in-nigeria-b y-type-and-gender/

[37] Katz, I., Routh, S., Bitran, R., Hulme, A. and Avila, C. (2014) Where Will the Money Come from? Alternative Mechanisms to HIV Donor Funding. BMC Public Health, 14, Article No. 956. https://doi.org/10.1186/1471-2458-14-956

[38] Zakumumpa, H., Bennett, S. and Ssengooba, F. (2019) Leveraging the Lessons Learned from Financing HIV Programs to Advance the Universal Health Coverage (UHC) Agenda in the East African Community. Glob Health Res Policy, 4, Article No. 27. https://doi.org/10.1186/s41256-019-0118-y

[39] Sanusi, A., Abdulazeez, A., Zubaida, F., Gadanya, M. and Lawal Jimoh, M. (2018) Prevalence and Pattern of Unintentional Domestic Accidents and Trauma amongst Children Attending Public Hospitals in Kano, Nigeria. Sahel Medical Journal, 21, 6-12. http://doi.org/10.4103/1118-8561.232787

[40] Wirtz, V.J., Forsythe, S.S., Valencia-Mendoza, A., Bautista-Arredondo, S. and Santa Ana-Téllez, Y. (2008) The Cost of Antiretrovirals; Maximizing Value for Money. Draft Working Paper (AIDS 2031). Results for Development Institute, Washington DC. https://r4d.org/wp-content/uploads/The-Cost-of-Antiretrovirals.pdf

[41] Tagar, E., Sundaram, M., Condliffe, K., Matatiyo, B., Chimbwandira, F., Chilima, B., et al. (2014) Multi-Country Analysis of Treatment Costs for HIV/AIDS (MATCH): Facility-Level ART Unit Cost Analysis in Ethiopia, Malawi, Rwanda, South Africa and Zambia. PLOS ONE, 9, e108304. https://doi.org/10.1371/journal.pone.0108304

[42] USAID Global Health Supply Chain Program-Procurement and Supply Management (GHSC-PSM, 2021) Country Approach-Nigeria. https://www.ghsupplychain.org/country-profile/nigeria 